\title{
Analisis Parameter Gap Dalam Tahapan Dekonvolusi Prediktif Guna Mereduksi Short Period Multiple dan Meningkatkan S/N Ratio pada Pengolahan Data Seismik Refleksi 2D Marine
}

\author{
Bella Chintiaa, Okto Ivansyah ${ }^{\mathrm{b}}$, Joko Sampurno ${ }^{\mathrm{a} *}$ \\ aProdi Fisika, Fakultas MIPA, Universitas Tanjungpura, \\ Jalan Prof. Dr. Hadari Nawawi, Pontianak, Indonesia \\ bProdi Budidaya Tanaman Perkebunan, Fakultas Pertanian, Politeknik Negeri Pontianak \\ Jalan Jenderal Ahmad Yani, Pontianak, Indonesia \\ *Email : Jokosampurno@physics.untan.ac.id
}

\begin{abstract}
Abstrak
Penelitian ini bertujuan untuk menentukan nilai gap terbaik dari salah satu parameter gap yang digunakan untuk mereduksi short-period multiple dengan metode dekonvolusi prediktif. Variasi nilai gap yang digunakan adalah 4, 8, 12, 16, 20, 24, 28, dan 64 ms. Berdasarkan hasil penelitian, diketahui bahwa gap 12 merupakan gap terbaik. Nilai gap 12 menghasilkan sp gather, penampang stack dan NTG (Near Trace Gather) yang lebih tajam dibandingkan dengan gap lainnya. Selain itu, dari spectrum analysis didapatkan sp gather dan penampang stack yang menunjukkan bahwa frekuensi terletak pada rentang nilai $10-80 \mathrm{~Hz}$, dan nilai spectrum amplitude seismik yang terkecil berkisar -21 s.d $0 \mathrm{~dB}$.
\end{abstract}

Kata Kunci : seismik refleksi, dekonvolusi prediktif, short-period multiple, reverberasi, gap

\section{Latar Belakang}

Metode seismik refleksi memiliki 3 tahapan utama, yaitu akuisisi (survey) data, pengolahan data, dan interpretasi data. Tahapan akuisisi data merupakan pengumpulan data dimulai sejak awal hingga survey akhir. Akuisisi data dapat dibedakan menjadi laut (marine), darat (land), dan transisi (transition). Tahapan pengolahan data merupakan kegiatan mengolah data seismik hasil rekaman dilapangan dan diubah ke bentuk penampang seismik. Salah satu tujuan pengolahan data seismik adalah untuk mengurangi noise sehingga mempertinggi signal to noise ratio (SNR) [1].

Salah satu poin tersulit dalam metode seismik refleksi adalah pengolahan data seismik laut. Pada data seismik laut bukan hanya sinyal informasi struktur bawah permukaan yang terekam tetapi juga noise yang dapat merusak kualitas data. Contoh dari noise koheren yang sering ditemukan pada data seismik marine adalah multiple. Multiple data seimik laut terdiri dari 2 kategori yaitu multiple bawah laut dan multiple gelombang interlayer [2].

Multiple ialah pengulangan refleksi akibat terperangkapnya gelombang seismik dalam air laut atau terperangkap dalam lapisan batuan lunak [3]. Multiple terdiri atas beberapa jenis diantaranya: short-period multiple dan reverberasi. Multiple sering kali mengganggu pantulan gelombang primer dan menyebabkan citra seismik menjadi buruk. Penghilangan multiple merupakan masalah yang telah lama didalami dalam eksplorasi geofisika [4].

Salah satu metode untuk menghilangkan short - period multiple dan reverberasi adalah dekonvolusi. Dekonvolusi merupakan suatu proses untuk meningkatkan resolusi temporal dari data seismik dengan cara mengembalikan wavelet yang terekam agar menjadi tajam [5]. Metode dekonvolusi berdasarkan operasi filter Wiener yang dapat digunakan yaitu dekonvolusi spiking dan dekonvolusi prediktif (dekonvolusi gap) [6].

Dekonvolusi gap merupakan dekonvolusi yang menggunakan prinsip prediction error filter yang didasarkan pada kenyataan bahwa multiple selalu dapat diprediksi dalam trace seismik. Dekonvolusi gap ini memiliki 2 parameter utama yaitu gap length dan operator length. Gap length adalah lebar defleksi yang lolos dari reverberasi dimana nilai gap merupakan besarnya waktu pada second zero crossing dari hasil autokorelasi input yang dimiliki [7], sedangkan operator length (OL) adalah lama reverberasi.

Pada saat melakukan proses dekonvolusi prediktif, tahapan yang penting adalah menentukan nilai operator length (OL) dan gap length (prediction distance). Penentuan kedua parameter tersebut diharapkan mampu mereduksi short period multiple secara maksimal. Pada pememilihan gap, nilai gap yang dipilih harus melebihi nilai interval dari data sample. Untuk memenuhi keperluan tersebut, pada penelitian ini dilakukan penentuan dan 
POSITRON, Vol. VII, No. 1 (2017), Hal. 25 - 33

http://dx.doi.org/10.26418/positron.v7i1.20783

analisis nilai gap yang terbaik pada proses dekonvolusi prediktif.

\section{Metodologi}

Tahapan pengolahan data yang dilakukan dalam tahap preprocessing antara lain reformat, geometry, denoise dan dekonvolusi prediktif. Reformat merupakan proses awal dari pengolahan data yang dihasilkan pada saat akuisisi data seismik. Pada tahap ini format data seismik diubah menjadi standar format internal software yang akan digunakan (ekstensi *dat).
ISSN: 2301-4970 ( print )

ISSN: 2549-936X (online)

Geometry bertujuan untuk mencocokkan antara file number (terdapat di observer report) dengan file record yang ada pada data seismik yang direkam dalam 1 shot (dalam pita magnetik atau media penyimpanan yang lain). Denoise merupakan tahapan untuk menghilangkan noise yang terdapat pada rekaman data seismik (biasanya berupa gelombang langsung dan gelombang permukaan). Gambar 1 merupakan contoh data input dari proses denoise yang berupa sp gather. Dekonvolusi prediktif digunakan untuk memprediksi error trace dalam memperkirakan reflektifitas seismik.

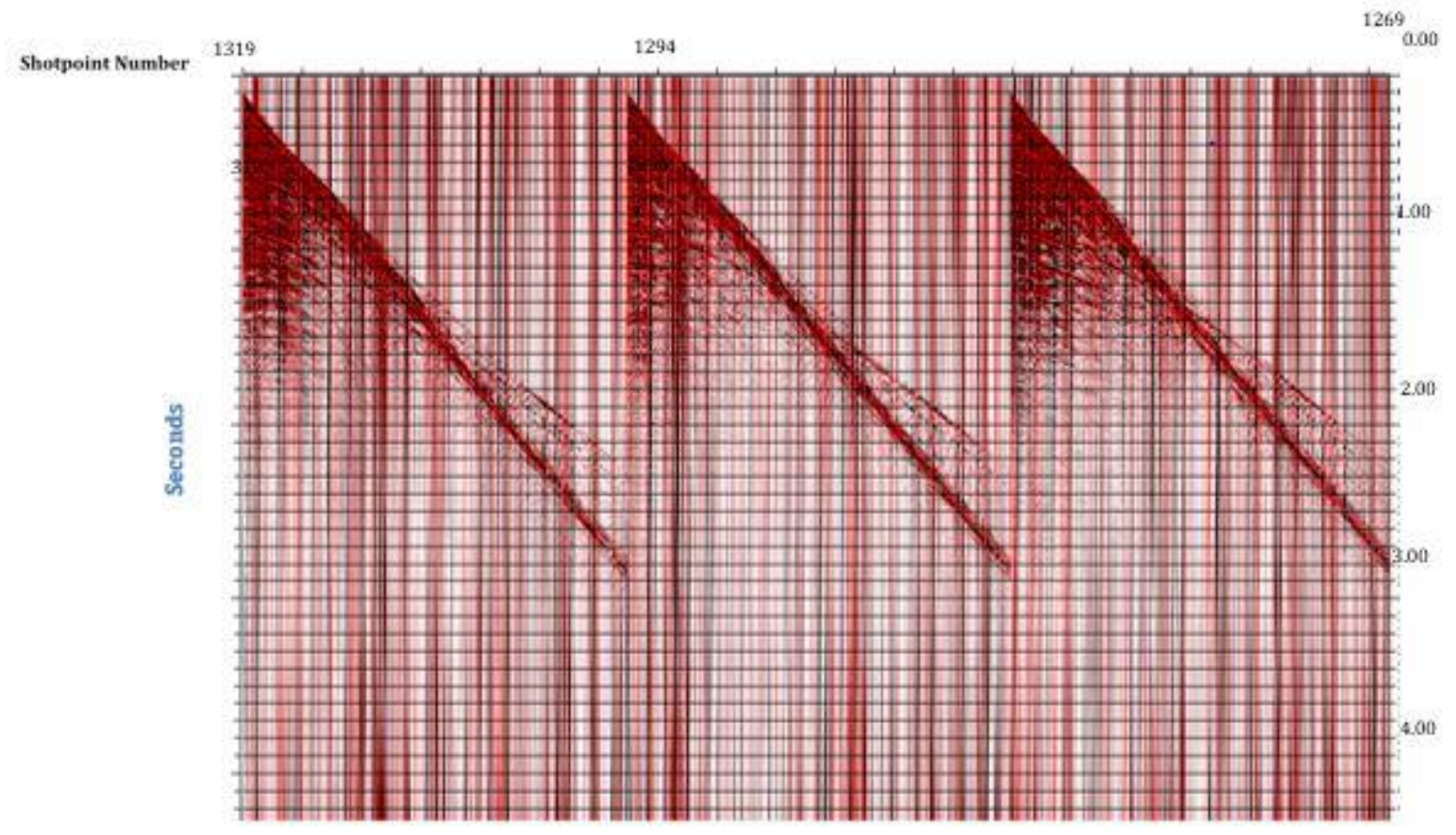

Gambar 1. Data Input (SP Gather)

Proses dekonvolusi prediktif dilakukan dengan cara mengurangi secara acak beberapa nilai gap. Nilai gap yang diuji dipilih berdasarkan nilai sample interval (SI). Dekonvolusi dinyatakan prediktif jika nilai gap lebih besar dari nilai SI. Data yang diolah memiliki nilai SI sebesar $1 \mathrm{~ms}$. Oleh karena itu, nilai gap yang dipilih adalah gap $4 \mathrm{~ms}, 8 \mathrm{~ms}, 12 \mathrm{~ms}, 16 \mathrm{~ms}, 20 \mathrm{~ms}, 24 \mathrm{~ms}, 28 \mathrm{~ms}$, dan 64 ms. Pengujian nilai gap yang dilakukan melalui proses trial and error. Pengujian ini didasarkan pada SP gather, spectrum analysis, autokorelasi dan stack. Pada pengujian ini, panjang operator $(O L)$ dibuat konstan sebesar $240 \mathrm{~ms}$.

\section{Hasil dan Pembahasan}

Pada penelitian ini, proses perbaikan data seismik dilakukan dengan menggunakan metode dekonvolusi prediktif. Metode dekonvolusi prediktif terdiri atas beberapa tahapan yaitu spectrum analysis, Auto-correlation, SP gather, stack, dan NTG (Near Trace Gather). Hasil pengolahan untuk masing-masing tahapan tersebut adalah sebagai berikut: 


\subsection{Spectrum Analysis}

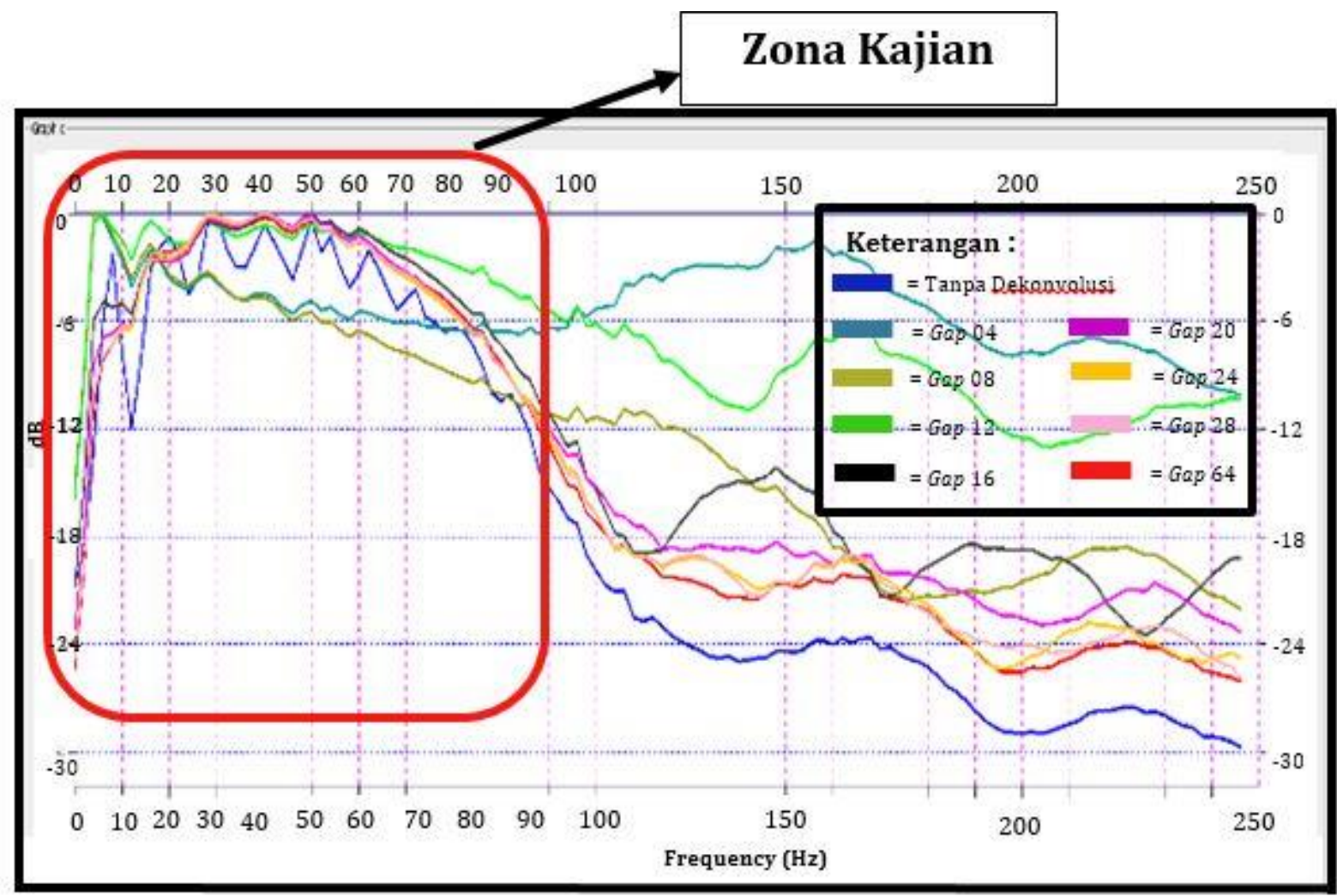

Gambar 2. Grafik Spektrum sebelum dan sesudah SP Gather, kotak merah merupakan spektrum yang dikaji

Gambar 2. menunjukkan hasil analisis spektrum pada sebelum dan sesudah SP (shotpoints) dekonvolusi. Pada sinyal tanpa dekonvolusi terlihat adanya pengaruh reverberasi yang cukup signifikan. Sinyal ini menunjukkan bahwa pada rentang frekuensi 0 $70 \mathrm{~Hz}$ amplitude spectrum berfluktuasi sangat kuat. Pada sinyal dengan gap 04 ms menunjukkan adanya fluktuasi pada rentang frekuensi $5-50$ Hz. Pada frekuensi di atas $100 \mathrm{~Hz}$ sinyal mengalami peningkatan yang cukup signifikan. Hal ini diduga sebagai efek dari reverberasi yang kembali muncul. Sinyal dengan gap $08 \mathrm{~ms}$ menunjukkan fluktuasi pada rentang frekuensi 0 $70 \mathrm{~Hz}$, dimana fluktuasi amplitude spectrumnya berkisar -15 hingga $0 \mathrm{~dB}$. Sinyal dengan gap 12 ms menunjukkan adanya fluktuasi pada rentang frekuensi $0-60 \mathrm{~Hz}$. Pada rentang ini terlihat bahwa efek reverberasi masih tampak dimana spektrum sinyal masih berfluktuasi namun tidak terlalu signifikan. Fluktuasi sinyal didapat pada rentang $10-80 \mathrm{~Hz}$ dengan rentang amplitude spectrum berkisar $-21-0 \mathrm{~dB}$. Sinyal dengan gap 20 menunjukkan bahwa spectrumnya berfluktuasi di sekitar frekuensi $0-60 \mathrm{~Hz}$ dengan rentang amplitudenya -23 hingga $0 \mathrm{~dB}$. Sinyal dengan gap 24 menunjukkan fluktuasi pada rentang frekuensi $0-50 \mathrm{~Hz}$, dengan rentang amplitude spectrumnya antara -24 hingga $0 \mathrm{~dB}$. Sinyal dengan gap 28 menunjukkan adanya fluktuasi pada rentang frekuensi $0-50 \mathrm{~Hz}$ dengan rentang amplitude spectrumnya berkisar -25 hingga $0 \mathrm{~dB}$. Terakhir, sinyal dengan gap 64 menunjukkan adanya fluktuasi dengan rentang amplitude spectrumnya berkisar - 26 hingga $0 \mathrm{~dB}$.

Gap terbaik dipilih dari sinyal yang memiliki rentang amplitude spectrum terkecil. Berdasarkan nilai gap yang diuji, amplitude spectrum terkecil dimiliki oleh gap 08 dan gap 12, sementara amplitude spectrum terbesar dimiliki oleh gap 64. 


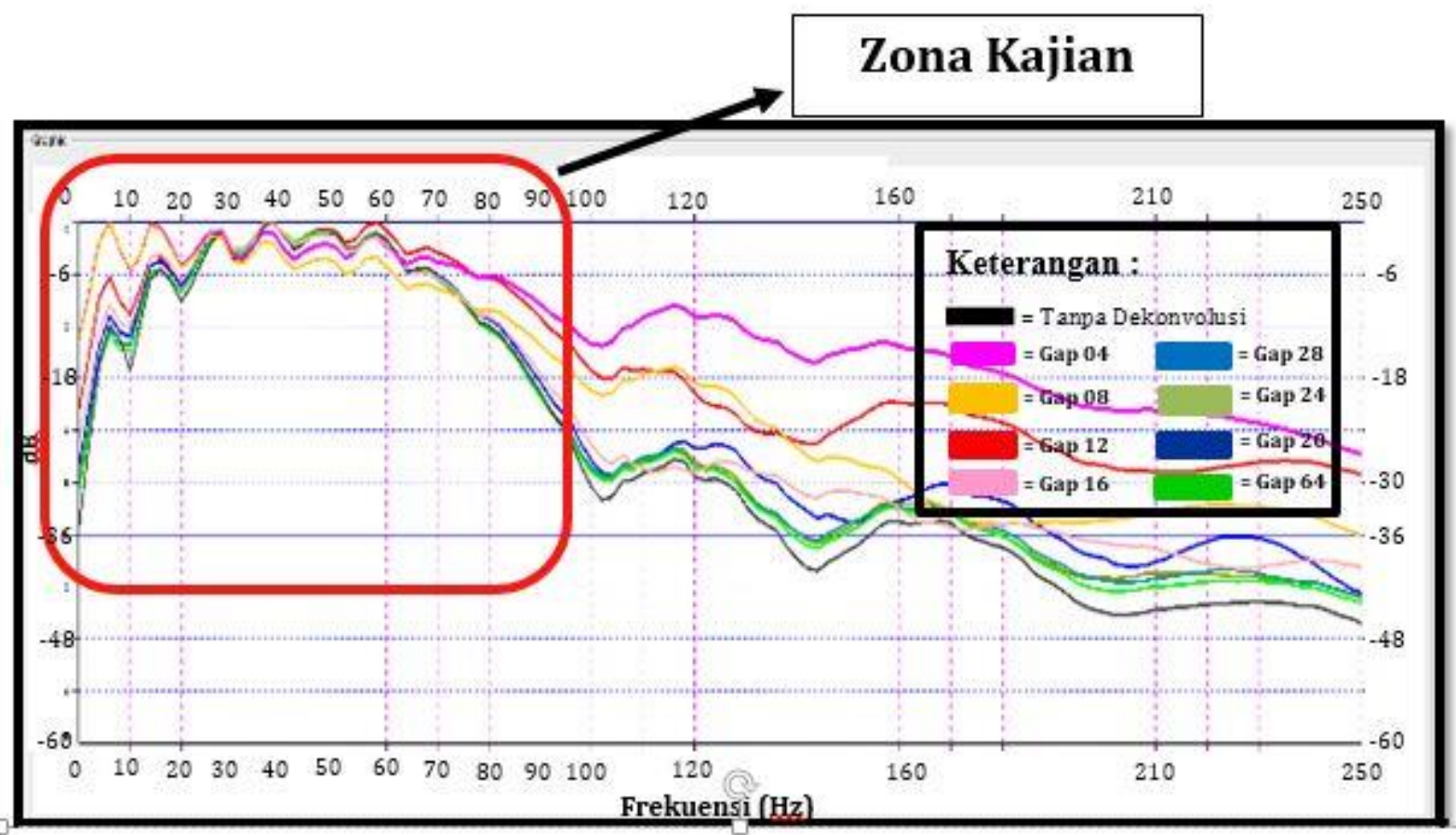

Gambar 3. Grafik Spektrum sebelum dan sesudah Stack dalam dekonvolusi prediktif, kotak merah merupakan spektrum yang dikaji

Gambar 3. memperlihatkan grafik spektrum pada sebelum dan sesudah stack dekonvolusi prediktif. Spektrum sinyal tanpa dekonvolusi menunjukkan adanya reverberasi yang terjadi pada rentang frekuensi adalah 25-50 Hz. Rentang nilai amplitude spectrumnya berkisar dari -35 hingga 0dB. Sinyal dengan gap $04 \mathrm{~ms}$ menunjukkan adanya fluktuasi pada rentang frekuensi $0-60 \mathrm{~Hz}$ dengan amplitude spectrumnya berkisar dari -13 hingga $0 \mathrm{~dB}$. Sinyal dengan gap $08 \mathrm{~ms}$ menunjukkan adanya fluktuasi yang tajam pada rentang frekuensi 0-50 Hz. Rentang amplitude spectrumnya berkisar dari -14 hingga 0dB. Spektrum sinyal dengan gap $12 \mathrm{~ms}$ menunjukkan penurunan efek reverberasi pada rentang frekuensi $0-60 \mathrm{~Hz}$. Rentang spectrum amplitude pada gap ini berisar dari -21 hingga 0 dB. Dari uji stack ini diketahui bahwa nilai gap terbaik diantara semua nilai yang diuji adalah gap 12.

\subsection{Auto-Correlation}

Analisis auto-correlation dibutuhkan karena dapat menguatkan analisis dalam pemilihan nilai parameter gap terbaik. Pemilihan tersebut bertujuan untuk mengetahui sejauh mana keefektifan dekonvolusi prediktif bekerja menghilangkan noise yang ada.

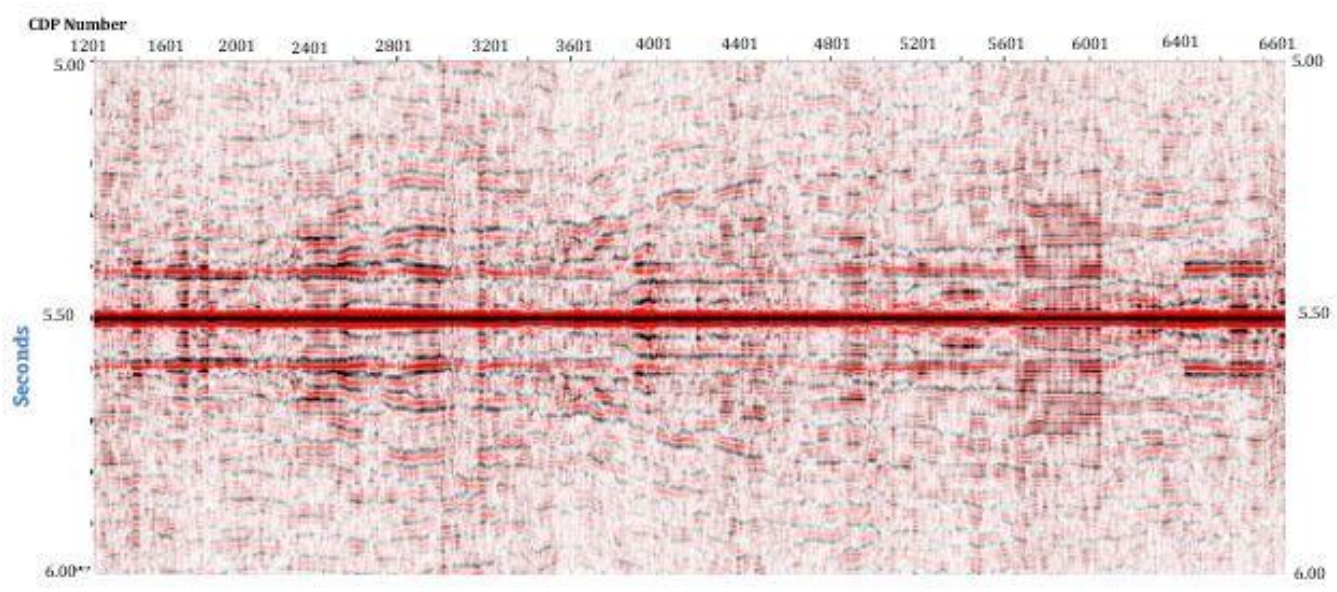

Gambar 4. Auto-Correlation pada sinyal tanpa Dekonvolusi 


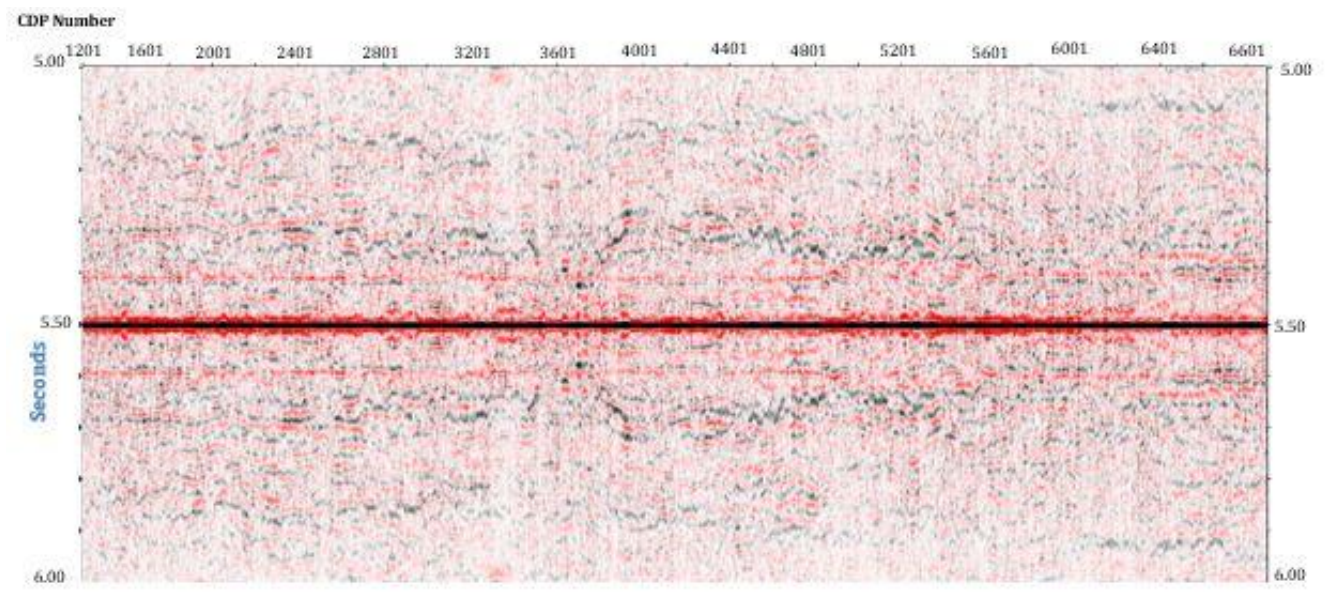

Gambar 5. Auto-Correlation pada sinyal dengan gap 12

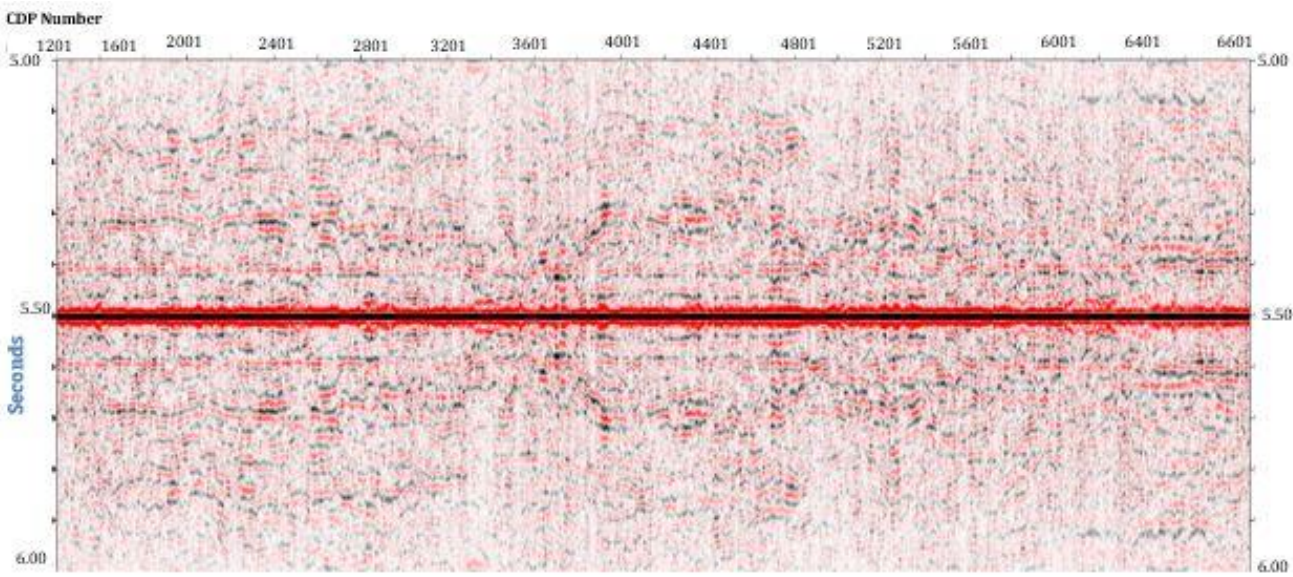

Gambar 6. Auto-Correlation pada sinyal dengan gap 16

Gambar 4 menunjukkan auto-correlation tanpa dekonvolusi prediktif. Sebagai pembanding Gambar 5 dan gambar 6 merupakan gambar autocorrelation dengan gap $12 \mathrm{~ms}$ dan gap $16 \mathrm{~ms}$ secara berurut-urut. Dalam auto-correlation lebar defleksi menunjukkan eksistensi data primer sedangkan diluar dari itu merupakan noise. Pada data tanpa dekonvolusi dapat diidentifikasi keberadaan noise, sementara pada gap 12 noise tersebut telah hilang. Pada gap 16 (Gambar 6) lebar defleksi lebih lebar dari gap 12 (Gambar 5). Data pada gap 16 ini juga masih banyak mengandung noise jika dibandingkan dengan data pada Gap 12.

Auto-correlation dikatakan stabil jika noise data tereduksi, namun data primernya tetap terjaga dengan baik. Kondisi ini akan memunculkan $S / N$ ratio yang meningkat. Berdasarkan pada Gambar 4, 5, dan 6 dapat diketahui bahwa data pada gap 12 memiliki lebar defleksi yang lebih tipis dan efek reverberasi yang jauh lebih sedikit dibandingkan dengan data yang lain. Analisis Auto-correlation ini memperkuat kesimpulan sebelumnya bahwa gap 12 mampu mereduksi noise dengan lebih baik dibandingkan dengan gap yang lain. Berdasarkan hal ini maka pada pembahasan berikutnya, data yang akan dibandingkan adalah data tanpa dekonvolusi dan data yang telah didekonvolusi dengan gap 12 . 


\subsection{Shotpoint Gather}

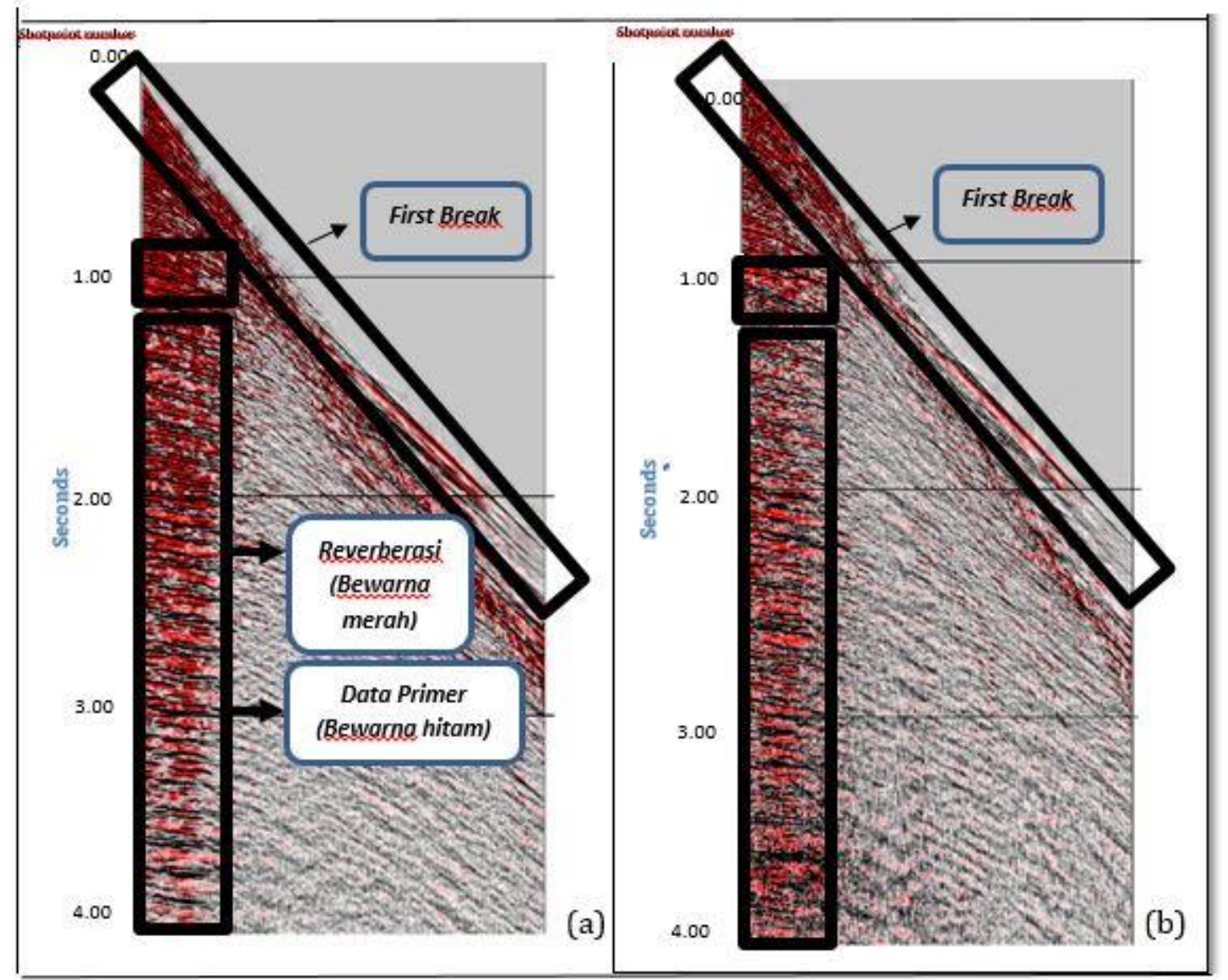

Gambar 7. (a) Shotpoint Gather tanpa dekonvolusi; (b) Shotpoint Gather pada Gap 12

Gambar 7(a) menunjukkan SP gather tanpa dekonvolusi prediktif sementara Gambar 7(b) menunjukkan $S P$ gather dengan dekonvolusi prediktif pada gap 12. Pada SP gather tanpa dekonvolusi (Gambar 7a) terdapat short period multiple pada rentang waktu antara $1 \mathrm{~s}-3,5 \mathrm{~s}$. Pada rentang waktu di bawah 3,5 s noise masih dapat terlihat namun tidak setajam noise di atas waktu 3,5 s. Refleksi primary terlihat pada rentang antara $0,8 \mathrm{~s}-2,8$ s. Pada $S P$ gather dengan gap 12 (Gambar 7b) short period multiple muncul lebih banyak dari Gambar (2a), namun data primernya terlihat lebih tajam. 


\subsection{Stack}

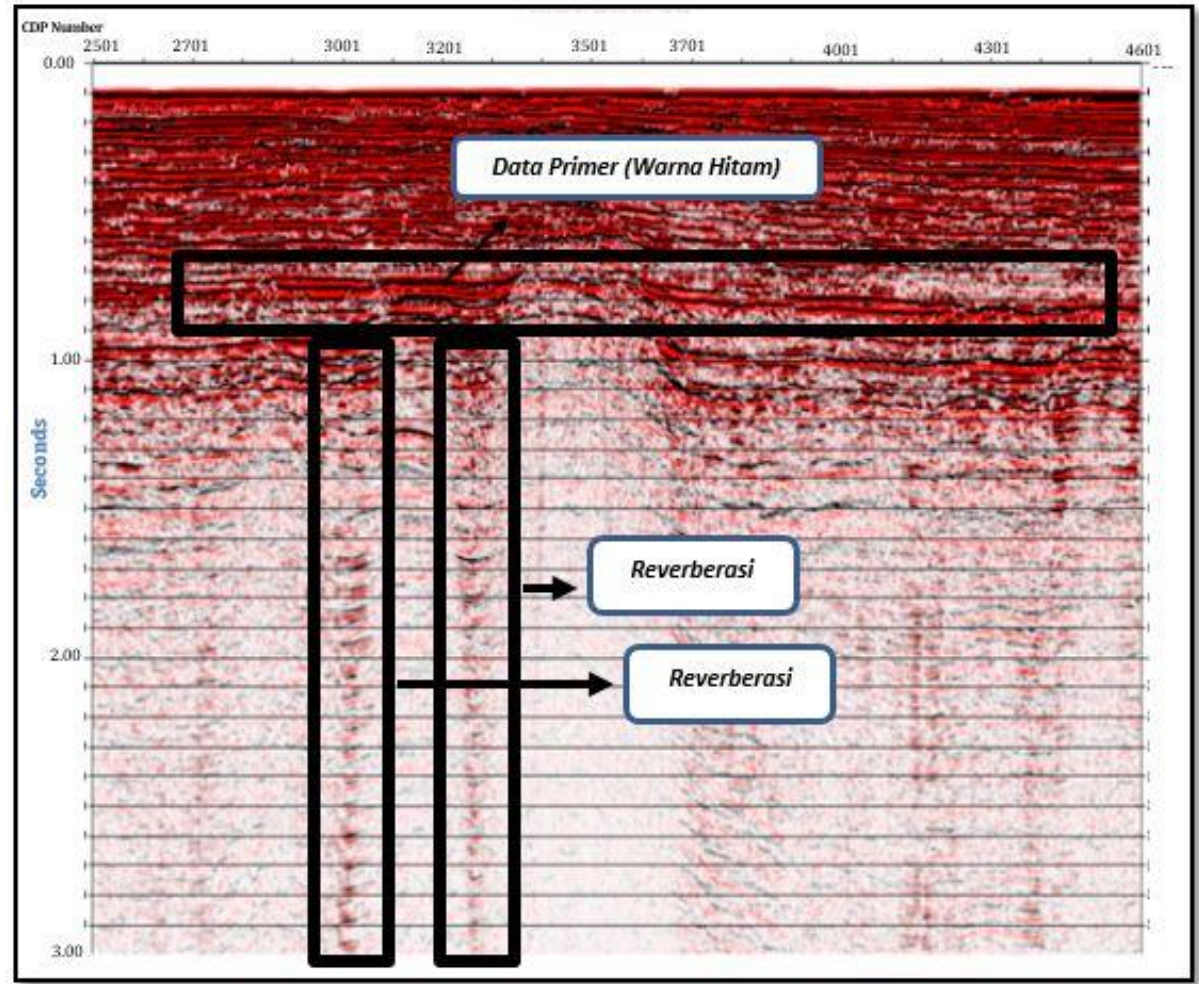

Gambar 8. Stack Tanpa Dekonvolusi

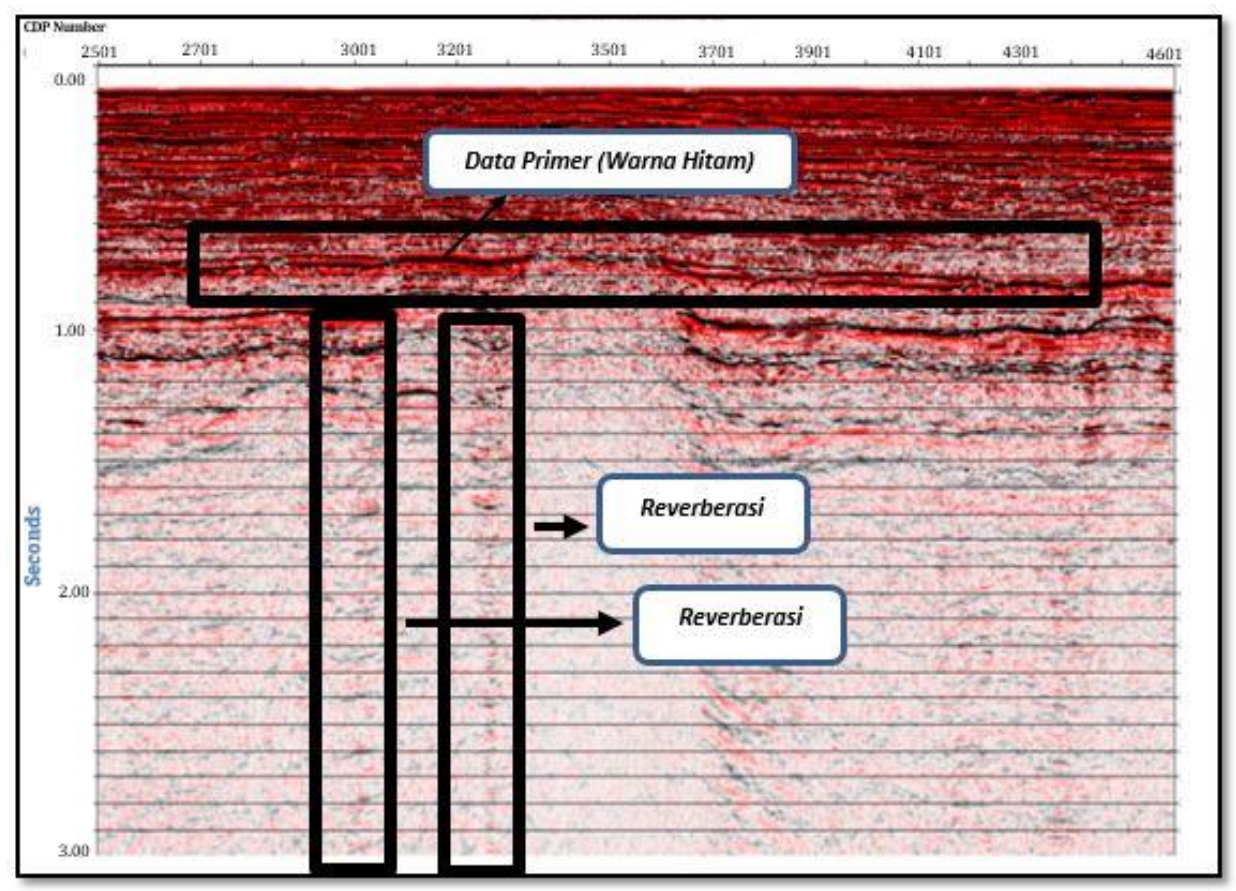

Gambar 9. stack pada gap 12

Gambar 8 menunjukkan stack tanpa dekonvolusi prediktif. Pada gambar tersebut terdapat banyak short period multiple pada near offset. Pada stack tersebut terdapat juga patahan yang menimbulkan efek reverberation sebagai pembanding. Sebagai pembanding, Gambar 9 menunjukkan stack dengan dekonvolusi prediktif pada gap 12. Pada gambar tersebut terdapat reverberation di rentang waktu $1 \mathrm{~s}-3 \mathrm{~s}$, yang belum tereduksi dengan baik. Namun, pada rentang waktu 1,2 s - 2 s reverberation sudah dapat tereduksi dan data primernya menjadi lebih tajam. 


\subsection{NTG (Near Trace Gather)}

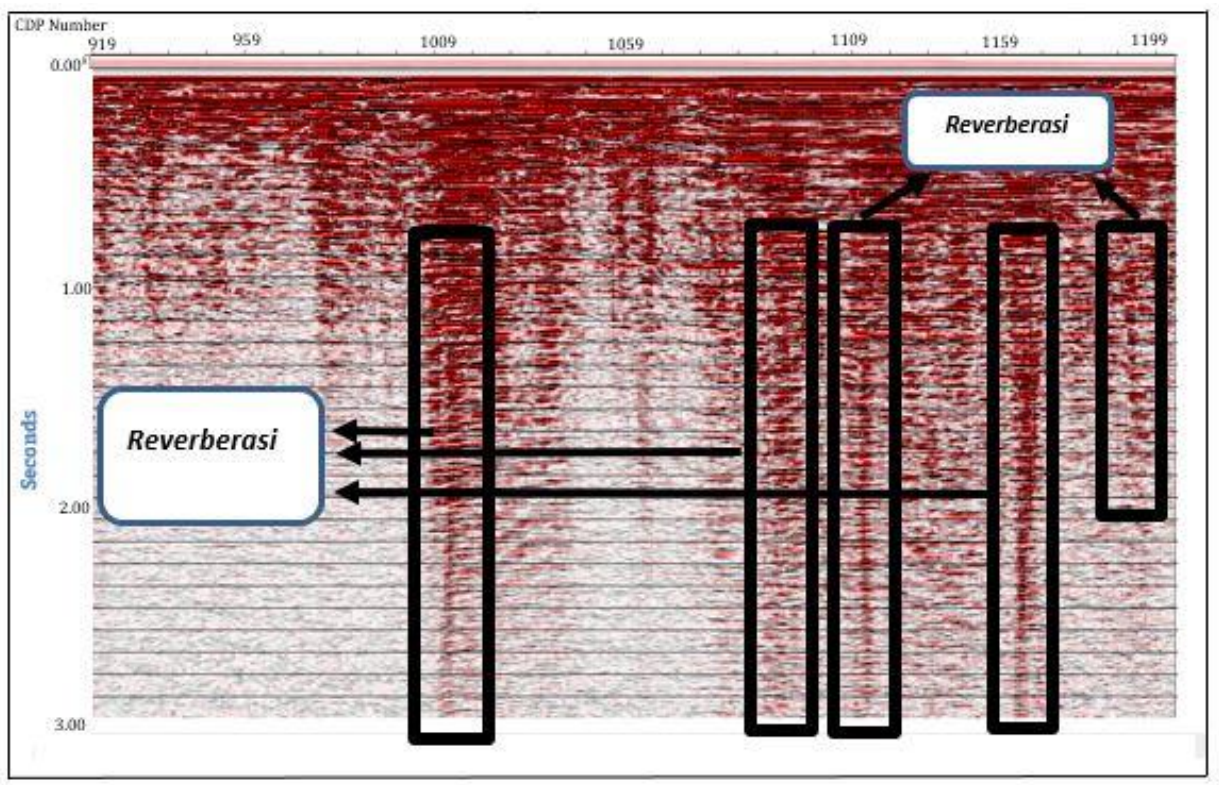

Gambar 10. NTG Tanpa Dekonvolusi

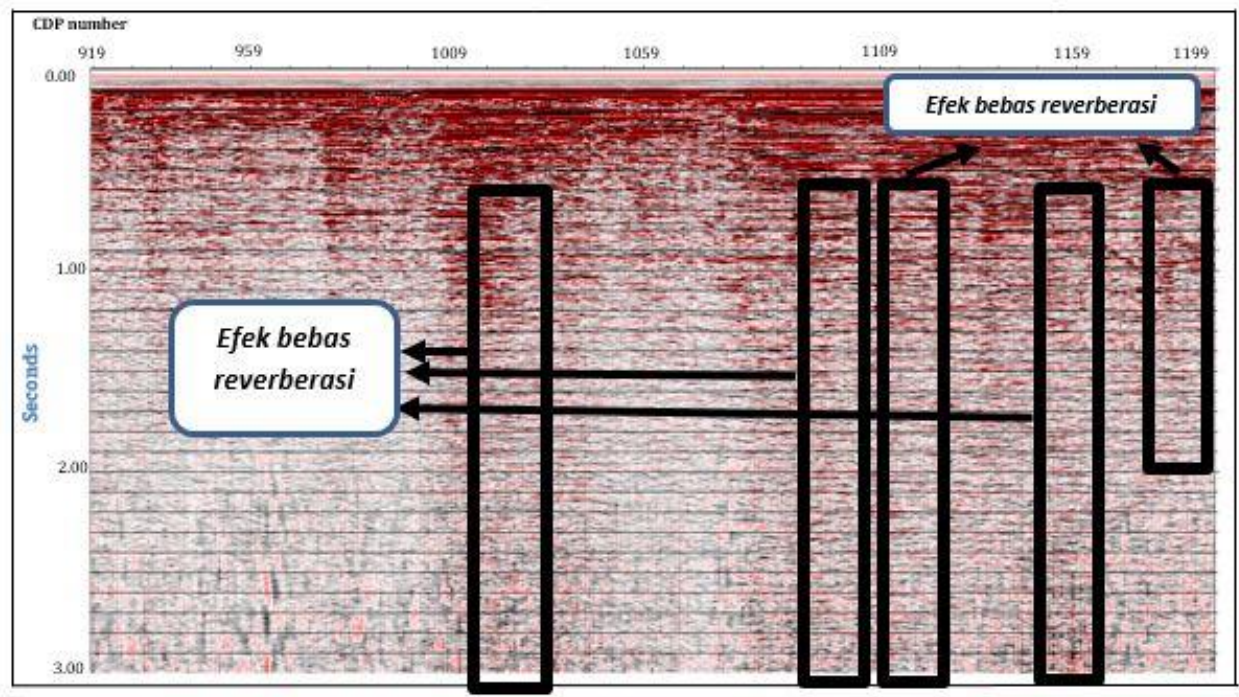

Gambar 11. NTG dengan Dekonvolusi pada gap 12

Gambar 10 menunjukkan NTG tanpa dekonvolusi prediktif. Sebagai pembanding, Gambar 11 merupakan NTG dengan dekonvolusi prediktif pada gap $12 \mathrm{~ms}$. Pada NTG tanpa dekonvolusi dapat terlihat reverberasi yang telah bercampur dengan short period multiple pada near offset. Untuk NTG dengan dekonvolusi prediktif pada gap 12 menunjukkan bahwa efek dari reverberasi yang bercampur dengan short period multiple tersebut telah tereduksi dengan baik. Namun kelemahannya, terdapat beberapa data primer yang ikut tereduksi. 


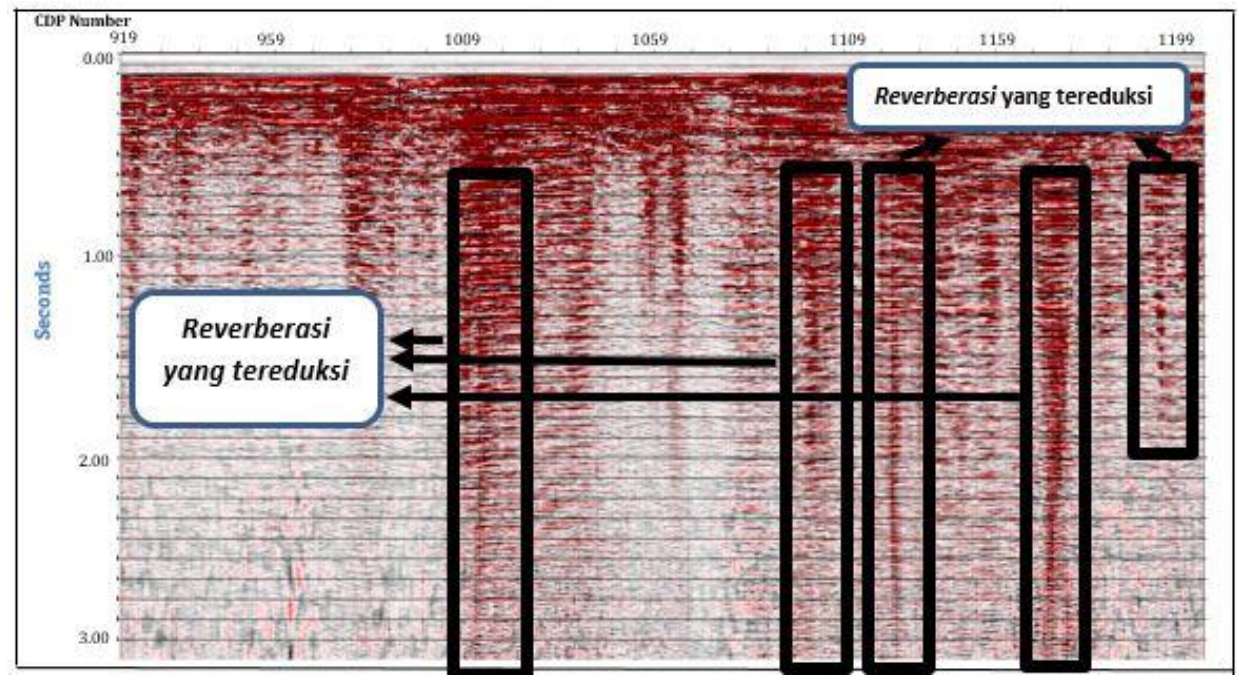

Gambar 12. Difference NTG pada gap 12

Gambar 12 menunjukkan adanya Difference NTG pada gap 12. Dikatakan difference karena data yang dihasilkan merupakan data dari pengurangan hasil input (sebelum dilakukan dekonvolusi prediktif) dan hasil dari dekonvolusi prediktif untuk gap 12. Dari gambar tersebut terlihat bahwa pada waktu 3s, short - period multiple dapat tereduksi walaupun tidak signifikan karena noise masih terlihat pada CDP number 1179.

\section{Kesimpulan}

Berdasarkan pembahasan diatas dapat disimpulkan bahwa penggunaan metode dekonvolusi prediktif ini dapat meningkatkan $S / N$ ratio dalam data seismik dan dapat mereduksi jenis noise short-period multiple. Parameter gap terbaik adalah gap 12 karena menghasilkan spectrum analysis dengan nilai spectrum amplitude seismik terkecil yang berkisar -21 - $0 \mathrm{~dB}$. Gap 12 juga menghasilkan sp gather, penampang stack, dan NTG (Near Trace Gather) yang paling tajam dibandingkan dengan nilai gap lainnya.

\section{Daftar Pustaka}

[1] Egbai JC, Atakpo E, Aigbogun CO. 2012. Predictive Deconvolution in Seismic Data Processing in Atala Prospect og Rivers State, Nigeria. Adv. Appl. Sci. Res. 2(1):520-529.

[2] Jian, X, and Sixin Z. Predictive deconvolution for Attenuation of Multiple Reflections in Marine Seismic Data Processing. Journal of Coastal Research 73.sp1 (2015): 310-314.

[3] Sukmono, S. 1999, Seismik Stratigrafi. Teknik Geofisika ITB, Bandung.
[4] Cao, Z. 2006. Analysis and application of the Radon Transform. [Thesis]. University of Calgari. Alberta

[5] Yilmaz 0. 2001. Seismic Data Analysis Processing, Inversion, and Interpretation of Seismic Data Volume 1. Society of Exploration Geophysics . Tulsa (US).

[6] Lines L. 1996. Suppression of Short Period Multiple - Deconvolution or Model Based Inversion ?. Canadian Journal of Exploration Geophysics. 32 (1):63-72.

[7] Peacock KL, Treitel S. 1969 Predictive Deconvolution: Theory and practice. Geophysics. 63:155-169. 